\title{
Knowledge exchange methods in practice: knowing how to design for older adults
}

\author{
LesleyJ. McIntyre and lan Ruaraidh Harrison
}

We are living in a dynamic and ageing world. This creates complex design challenges if a supportive built environment is to be shaped inclusively for all users. Understanding user requirements and the appropriate exchange of this knowledge, via methods that appeal to Built Environment Professionals (BEPs), is crucial in this pursuit.

There is a vast amount of design information from various resources such as legislation ${ }^{1}$ and design guidance. ${ }^{2}$ Each of these sources, concentrating on different aspects of built environment design, has the potential to be a useful tool for designers. Unfortunately, a lot of this knowledge remains under utilised. Information becomes 'lost' in exchange and therefore fails to impact on design. Previously in arq, a lack of knowledge sharing infrastructure within our professions compared to others was identified. ${ }^{3}$ In addition, recent literaturebased reviews have highlighted a disconnect in knowledge transfer between academia and practice. ${ }^{4}$ Others, focusing on case studies examining the sharing of information and knowledge management within practices, have stated 'the literature is so extensive and dense that it is difficult in a busy practice to find time to study it and work out what to do..${ }^{5}$ Barriers in BEP knowledge exchange still exist between practice and research in 2016.

Appropriate exchange of knowledge between academic forms of user research, policy, and practice is essential for effective 'real-world' design impact. As opposed to understanding theories of learning, ${ }^{6}$ there is limited evidence of the successes and limitations of knowledge exchange within professional practice. In academic research, this evidence is important, as impact outside the academic community is a major factor on Research Councils UK (RCUK) funding agendas. ${ }^{7}$ In design practice, it is important for the progression of the profession and the state of the art in terms of innovation and efficiency. ${ }^{8}$ Therefore, we ask what is effective in the exchange of knowledge into professional BEP practice?

This article presents BEP's viewpoints on knowledge exchange in the context of designing for older adults. Purposeful conversations, which evolved into semi-structured interviews, were conducted with ten participants working within a range of types and sizes of architectural practice in Scotland. An extensive questionnaire, built from conversation analysis, was designed and responses were received UK-wide from thirty-five BEPs.

Findings provide insight into fundamentals of good communication, the desire for structured knowledge, the value of contextual guidance, the importance of a visual format for BEPs, and the need for guidance to support client motivations. An additional thread of discussion investigates the BEP's reflections on direct engagement with building users. Overall, this article contributes to improving our understanding of BEP's viewpoint on knowledge exchange and presents principles for the refinement of future sources of guidance.

\section{Knowledge exchange, design requirement elicitation,} and built environment practice

Built environment professionals including, but not exclusive to, architects, engineers, interior designers, policymakers, and expert consultants (for example, occupational therapists) collaborate as a project team. They inherently combine different types of knowledge from multidisciplinary sources ${ }^{9}$ and experiential knowledge (gained through practice and personal experience).

Built environment research is producing numerous resources identifying user requirements for use within the design process. Some of these studies have measured the impact of the environment on quality of life, ${ }^{10}$ investigated the design of homes and the effect on older people, ${ }^{11}$ and explored spatial layout and patterns of space use. ${ }^{12}$

\section{Design requirement elicitation through direct user engagement}

BEPs also engage with users to elicit requirements and take part in different knowledge exchange flows to develop understanding. Developing this understanding is fundamental, as 'the production of architecture demands an ability to imagine how others may use and experience a building. ${ }^{, 13}$

In designing for the inclusion of people, 
researchers and designers are increasingly recognising the importance of engaging and collaborating with users in 'real-world' contexts in the elicitation of user-requirements. ${ }^{14}$ The benefits of participatory design have been acknowledged as advancements made to the creative process, the service provided, and project management with longer-term effects also recognised. ${ }^{15}$

It is acknowledged that designers find inspiration and are influenced by daily life occurrences and interactions. ${ }^{16}$ Engagement with users is evidenced in the works of Christopher Alexander who values the user as the building expert $;{ }^{17}$ Herman Hertzburger who believed the architect's role was to provide a spatial framework to be eventually filled in by the users $;^{18}$ Joshua Prince-Ramus who promotes the agency of architecture, ${ }^{19}$ and Bjarke Ingels who believes that architecture should be informationdriven design. ${ }^{20}$ Whilst there is a clear agenda to understand user need, there is an ever-evolving set of ethical issues and methodological challenges.

\section{Practice frameworks in support of the elicitation of users' needs}

Various BEP practice frameworks exist worldwide to guide the design process. The elicitation of user needs within built environment design in the UK is promoted within the Royal Institute of British Architects (RIBA) Plan of Works. ${ }^{21}$ Within the RIBA framework, each key stage relates to key information exchanges. It has been recognised that BEPs and their clients make knowledge sharing a vital part of the design process. ${ }^{22}$

\section{Flows of knowledge exchange}

In addition to the continual knowledge exchange flow between BEPs and their clients, there are other knowledge exchanges within Built Environment Design Practice. These occur within a BEP team (that is, between colleagues), between Academia and Practice (between researchers and practitioners) and between BEP teams (between practices).

Within design practice, many methods for sharing knowledge amongst teams have been identified. ${ }^{23}$ This includes techniques such as wikis, storytelling, exploiting existing documents, data mining, communities of practice, mentoring, and workspace design. Emphasis has been placed on the informal 'tradition for architectural staff to exchange opinions about projects in front of drawing boards in the offices'. ${ }^{24}$

Research is recognised as being a component of what it means to be a professional and is a vital part of the design process in practice. ${ }^{25}$ In academia, methods of public engagement and effective knowledge exchange are key elements in executing a successful research project. In support of this, RCUK are motivated to fund research projects that have impact, which they define as 'the demonstrable contribution that excellent research makes to society and the economy'. ${ }^{26}$

Knowledge exchange between practices is active. It can be identified as happening within monographs (such as 's.m.l.xl' ${ }^{27}$ or 'yes is more ${ }^{, 28}$ ), diverse journals (such as arq, The Architects Journal, and Blueprint) and professional institutes (such as RIBA). What is more, there is a UK agenda to promote practice-to-practice knowledge exchange and this is evident in various design hubs such as the Design Council and The Royal Incorporation of Architects in Scotland (RIAS) chapter groups. Although we can identify extensive evidence of this type of exchange, the existing research documentation of it is not as evident as the research of knowledge exchange within BEP Practices.

\section{Challenges of knowledge exchange}

During the BEP's search for design information, knowledge can be gathered from various sources including, but not limited to, precedent studies, guidance, legislation, and professional training. Each of these resources, concentrating on different aspects of built environment design, has the potential to be a useful tool. However, knowledge exchange within the BEP is a complex task, with challenges.

Presentation format has been highlighted as an important factor in determining how successfully information is exchanged. It was emphasised how useful Danish architects found non-textual methods of communicating (such as the diagram). ${ }^{29}$ However, it is recognised that format is not the only factor: 'merely changing presentation format will not overcome existing barriers to design information transfer'.$^{30}$

Other studies widened the search and raised issues in relation to the practice culture,$^{31}$ different types of learning, ${ }^{32}$ and codification of tacit knowledge and experience. ${ }^{33}$ Decision-making in architectural practice $^{34}$ and constraints in the seeking and application of information ${ }^{35}$ have all been identified as having an impact on how knowledge is exchanged and utilised. Knowledge in practice is composed of both the technical, quantifiable, and measurable data and the tacit, qualitative, and subjective information. Codification of the less formal tacit knowledge has also been raised as a weakness in BEP practice. ${ }^{36}$

Although the 'intimate relationship between research and design innovation' is acknowledged in practice,${ }^{37}$ it is not always a component of the design process that is known by clients. ${ }^{38}$ Furthermore, different knowledge cultures in academia and practice have created barriers to knowledge exchange ${ }^{39}$ It is identified that research needs to design outputs to 'bridge the gap between researchbased knowledge and practice-used knowledge' ${ }^{40}$ However, it is difficult for researchers to evaluate how to deliver knowledge to have impact. ${ }^{41}$

It has been highlighted that 'a preference for academic knowledge exchange to take place via scholarly communication and journal articles' is a problem. ${ }^{42}$ By challenging the academic community to be more accepting of design, new journals such as Evidence Based Design (EBD) illustrate a new movement within design and research knowledge exchange. The motivation is clear: 'Reliable and unbiased knowledge about client requirements, along with user needs and behaviour, are also important in 
improving design quality and performance. A structured process (i.e. a research process) is most effective in gaining this knowledge. ${ }^{, 43}$

\section{A user study}

The objective of this article is to contribute understanding of BEP's reflections on knowledge exchange. Two methods were adopted: purposeful conversations $^{44}$ and an online questionnaire. ${ }^{45}$

\section{Purposeful conversation}

Purposeful conversation, ${ }^{46}$ which developed into a semi-structured interview, ${ }^{47}$ was used to 'set the scene' of how contemporary design practice is working to design for the needs of an ageing population (that is, what methods of knowledge exchange are being used and what their perceived successes and limitations are). This method was used in the first instance to remain open and to avoid the limiting the potential of the findings. Conversation topics focused on participants' role(s), the experience of designing for older people, resources used, and training received. Purposeful conversations took place in the participants' workplace, in a quiet meeting room. Each of the conversations took approximately 30 minutes and were recorded and later transcribed for analysis.

Purposeful conversation participants, thirty female and six male, were recruited via a professional architectural newsletter and were located in Scotland. Interviewees were Built Environment Professionals and the sample was found to be inclusive of architects (nine) and an interior designer. All participants had been involved in designing a broad variety of buildings from concept to completion, with the length of professional experience ranging from five to twentyfive years. The practices they worked for ranged in size (from less than five staff members to more than sixty) with various areas of expertise.

The conversational data was analysed by using the constant comparison technique of Grounded Theory. ${ }^{48}$ Using Dedoose (software for analysis of qualitative and mixed methods research), the data was open-coded to produce an initial code list, which was reworked until the analysis reached theoretical saturation with respect to the amount of information.

\section{Online questionnaire}

To increase the validity of findings that emerged from the conversations, by having a wider reach (in terms of location and numbers), a questionnaire was designed. Key questions were developed from analysis of the conversations and related back to the major research question. The questionnaire was launched online through Bristol Online Survey. It took approximately $25^{-}-30$ minutes to complete, with the option to pause and return at any time.

Questionnaire respondents, twenty female and fourteen male (one preferred not to answer), were recruited: via email (16); social media (10); by colleague recommendation (4); and through 'other' sources (4). Respondents were based in offices spread over the UK in: England (18); Scotland (13); Wales (1); and Northern Ireland (1). Twenty-one respondents worked for private practices, eleven for local authorities, and one worked within a government ministry. Respondents were Built Environment Professionals and the sample was found to be inclusive of Architecture (17), Occupational Therapy (6), Construction (3), Academia (1), Interior Design (1), Access Consultancy (4), and Health and Safety (1). Two preferred not to answer. All participants had been involved in designing a broad variety of buildings from concept to completion. The length of professional experience ranged from under one year to fifty years.

This method was successful in that it had a broader reach, in terms of participants' location and in terms of participants' professional role (that is, not just architects). However, it was still limited in terms of its response number $(n=35)$.

The questionnaire data was analysed through qualitative textual analysis methods (memos, question summaries, and answer counts). ${ }^{49}$ Questions using Likert-like scales of agreement were presented using divergent stacked bar charts. ${ }^{50}$ Statistical tests were not used due to the controversy surrounding statistical approaches to ordinal data and the response size, which was deemed too small to find any statistical reliability.

\section{Insight from the 'front line' of practice}

BEPs reported on their experiences of using a wide range of published guidance materials ranging from technical and regulatory guidance, to specialist guidance on designing for specific populations. They also reported a range of methods for working with guidance including printed material; however, there was a clear preference expressed for access via online and PDF formats [Table a]. Internet searching was identified as a valuable source for gaining access to a variety of design guidance. However, a 'simple one-stop source for designers and regulators' (Questionnaire Respondent $[\mathrm{Q}] 18$ ) was highlighted as an unmet desire.

BEPs also reported on other sources of knowledge including precedent study [1] and direct user engagement.

Many BEP professional bodies prescribe a minimum amount of time spent in documented continual professional development (CPD). Unsurprisingly, training was highlighted as a key part of most questionnaire respondents' professional practice (29 of 33 with 2 preferring not to answer), with most (16) taking on more than 26 hours per year. Specialist CPD focused on older people, wellbeing, and the built environment emerged as an effective resource in BEP practice. Sixteen of the seventeen BEPs who reported having completed this sort of training affirmed that it influenced design decisions and attitudes towards design regardless of building type.

The discussion of findings that follows presents BEP's viewpoints on knowledge exchange methods. The method highlighted practical issues by specifically focusing on one scenario, designing for 


\begin{tabular}{lr}
\hline 'What is your preferred format to gain access to design guide resources?' & 13 \\
\hline PDF read on Computer & 6 \\
PDF printed & 11 \\
Online Resource (e.g. Website) & 1 \\
Computer Software & 1 \\
Book & 0 \\
CPD Seminar or Formal Training & 0 \\
Design Meetings & 0 \\
Expert Advisor & 2 \\
Other: 'All of the above, CPD needs to come in all sorts of forms.' (Q20); 'From the collective & \\
knowledge and experience within our office' (Q01) &
\end{tabular}

Table a. Count of Questionnaire Respondents preference for guidance formats. (non-mutually-exclusive multiple choice

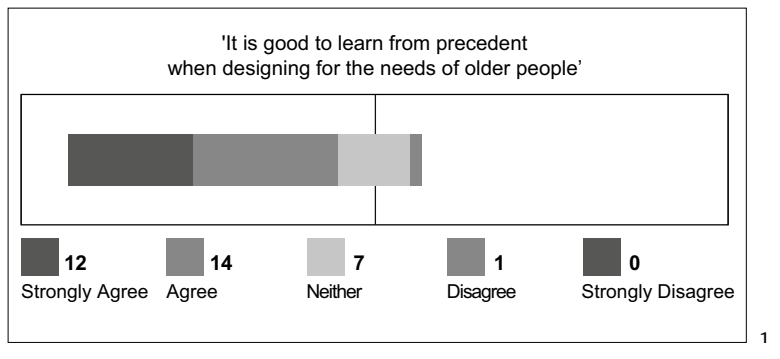

the requirements of older people. Whilst it is important to understand these findings in this context and some points remain specific to that scenario, the findings also relate to the broader context of all guidance used by these professionals. This discussion highlights principles for the future development of knowledge exchange over five sections: the fundamentals of 'good' communication, the desire for structured knowledge, the value of contextual guidance, the importance of a visual format for BEPs, and the need for guidance to support client motivations. An additional thread of discussion investigates the BEP's reflections on direct engagement with building users.

\section{Good practice in published and presented information} BEPs highlighted their appreciation of some basic forms of good practice in both published and presented information. It was reported during both interviews and questionnaire responses that not all current guidance meets these standards of good practice and BEPs agreed that current guidance can be confusing [2].

When asked to consider what made a piece of guidance good, a desire for clarity was evidenced by statements such as: 'Something that is clear and uncluttered' (Q25); 'Clear, concise, consistent guidance' (Q14); 'Easy access and plain English' (Q11); and 'readable' (Q10). Some BEPs reported frustrations caused by current guidance being 'vague on specifics' (Q19), or containing truisms: 'Occasionally guides contain well-meaning waffle' (Q31). The time constraints put on professionals in practice leads to a tough environment where there is little tolerance for verbosity.
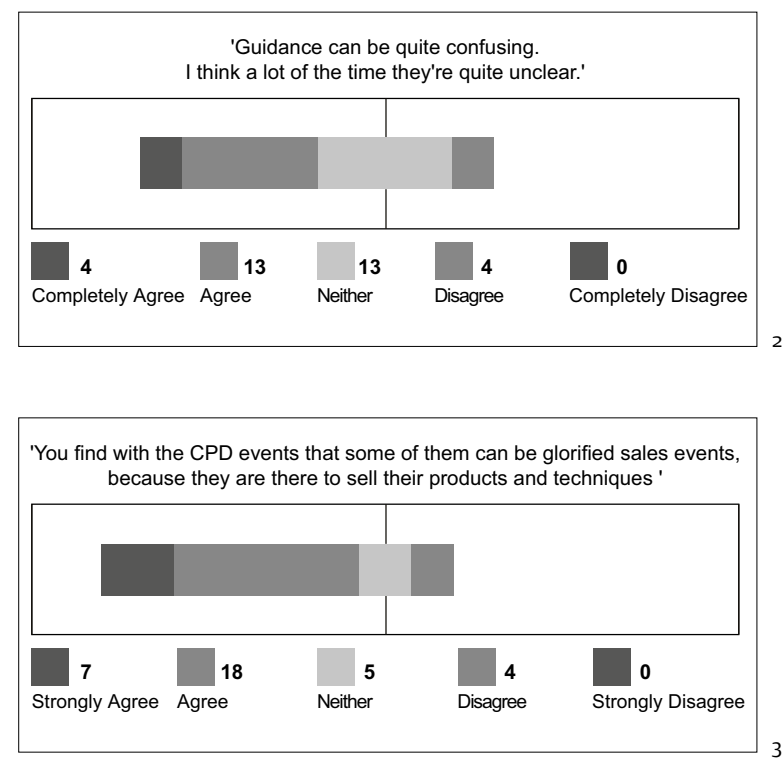

\begin{tabular}{|c|c|c|c|}
\hline $\begin{array}{l}\text { Count of } \\
\text { questionnaire } \\
\text { respondents' } \\
\text { agreement with the } \\
\text { value of precedent } \\
\text { study. }\end{array}$ & $\begin{array}{ll}2 \text { Count of } \\
\text { questionnaire } \\
\text { respondents' } \\
\text { agreement with } \\
\text { experiencing a lack of } \\
\text { clarity in quidance. }\end{array}$ & 3 & $\begin{array}{l}\text { Count of } \\
\text { questionnaire } \\
\text { respondents' } \\
\text { agreement with an } \\
\text { experience of a sales } \\
\text { bias to CPDs. }\end{array}$ \\
\hline
\end{tabular}

What I find with a lot of the guidance is, they pack it out with a lot of information. But there's only really a couple of paragraphs that are really important, that you need to read. I find that some of the best packs that you read, they're bullet points telling you this is what's required. (Interview Participant [I]08)

Citation was highly valued. Respondents highlighted the opportunity to gain access to further information relevant to the topic matter (Qs07, 04, $27,16)$ and material 'backed by evidence' $(\mathrm{Q} 29)$ as elements that would be a useful component of both design guidance and design training. A BEP further praised material that itself 'contains appropriate examples where necessary’ (Q10).

Several of the BEPs highlighted a problem with some of the training they received as being commercially driven. One interviewee explained, 'You find with the CPD events that some of them can be glorified sales events, because they are there to sell 
their products and techniques' (Io1). The questionnaire respondents showed high agreement with this statement [3]. Another added, 'I think a lot of the issues with CPDs, is they're not that engaging' (Ro8). This biased agenda and curriculum for training events led to calls from respondents for training which was 'not product focused' (Q21) and which did not 'push a particular product' (Q16). An unbiased educational focus, as opposed to a sales focus, was preferred.

When reflecting on what makes a good CPD, respondents put an emphasis on the performance and experience of the trainer. They highlighted a desire for 'Engaging, enthusiastic and knowledgeable' (Qo8) presenters and that trainers should have practical and research experience to help both lead and engage with the audience (Q29). A knowledgeable and practised 'expert' (Q25) presenter who 'is keen to work with the class to help their understanding and hopefully help create ideas' (Q25) was desired.

Elements of good teaching practice were highlighted in several cases: interactive workshop formats (Qso1, 21, 25); robust debate (Q32), and the use of learning outcomes (Qs10, 22). Whilst a 'Short, sweet and to the point' (Qog) presentation, was desired by some, a 'Loose format, which permits questions as the presentation proceeds' (Q23) was also preferred in some contexts. The need for variety and a 'Range of theoretical and practical sessions' (Q20) was identified.

For good practice in published documents: citation of information sources and clarity and use of clear language were valued. For presented information: an unbiased agenda, experienced and engaging presenters, and good teaching practices such as the use of learning outcomes were highlighted. Despite these being established criteria, it is seen as significant that practitioners highlighted these in relation to the current state of guidance.

\section{Structured knowledge}

Dealing with the quantity of guidance was raised as a challenge for some: 'From a designer's point of view, one of the biggest hurdles I've found is there's too much guidance' (Io2). The split response in agreement from questionnaire respondents shows this isn't an opinion shared by all [4]. Time pressures in the professional working environment, and the range of information sources, mean that systematic information sources were deemed necessary. It was explained, 'you have to be quite systematic in comparing guidance to understand how some might contradict each other' (Q24).

The requirement for options to explore different levels of 'good all-encompassing information' (Q07) was identified. This highlighted that both brief information and more detailed description need to be accommodated. Additionally, 'Clear indexing' (Q13) and search-based functions ( $\left.\mathrm{Q}_{23}\right)$ were identified as features that would improve the efficiency of using resources. Other ways of dealing with this issue included printing hard copies as an attempt at 'striking the balance of using it and designing' (Io1).

Guidance on user requirements is sought throughout all design stages [table b] 'depending on what is required at the time' (Q17) and as design is an 'iterative process' (Q29). When guidance is not well structured or codified it becomes more difficult to refer to within these ongoing processes. It is important that pieces of guidance are 'easy to find' (Qog).

\section{Information in context}

The holistic nature of design decisions and the myriad of competing demands on a design are recognised as intrinsic parts of the process. These demands attach two specific requirements onto understanding any recommendations contained within guidance in context: understanding the justification of a recommendation and

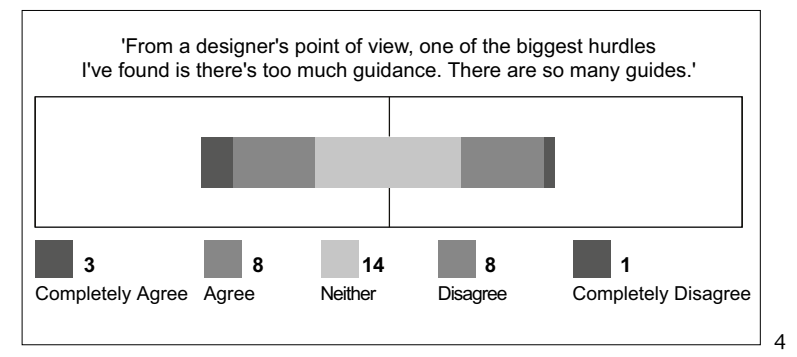

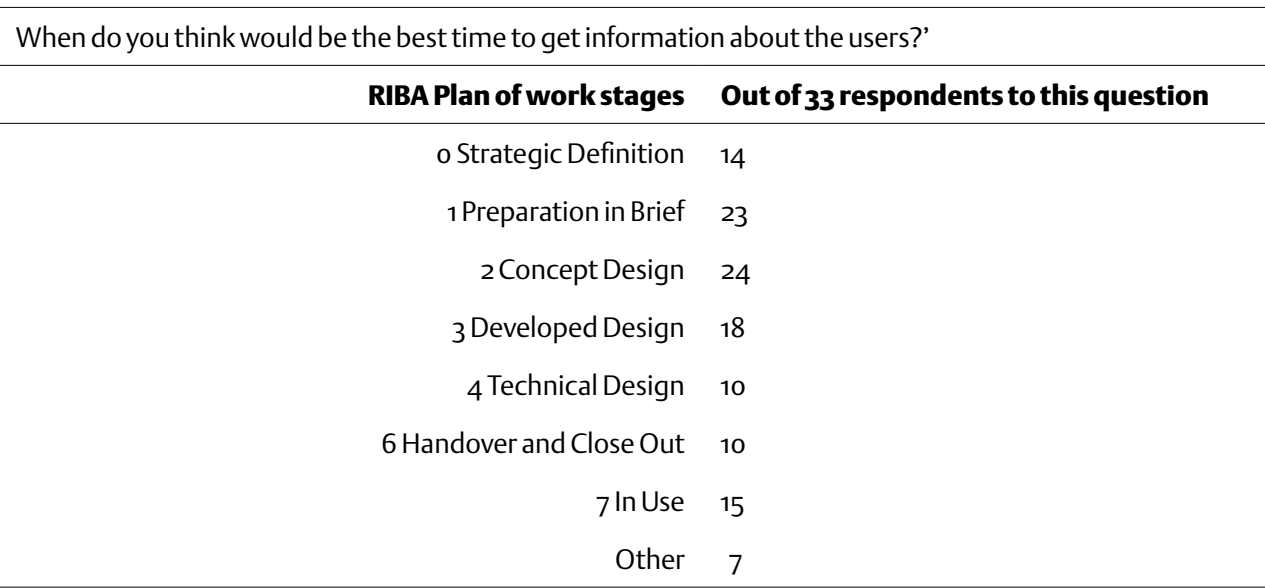


understanding the problems they address.

Different pieces of guidance provide different levels of recommendation. Understanding the justification of a recommendation (that is, whether it helps meet legal requirements, helps quality of life, helps profitability) is key to a BEP applying it appropriately. Frameworks of requirements 'e.g. essential, recommended, good to have etc.' (Q14) was suggested as a key way for BEP's to comprehend this.

Respondents highlighted a desire to comprehend the problems as well as proposed and recommended solutions. A BEP explained, 'it's the context that helps us to understand' (Io2).

You should be able to relate to it more and I don't think the regs make it easy to empathise, you are just ticking a box. [...] We need the reasons as to why we are supposed to design something in a certain way. That way we can come up with better, more aesthetically pleasing and technically relevant solutions.' (Io1)

Reflecting on one particular piece of guidance another interviewee raised a similar desire: 'basically [it] tells you what you should do, but it doesn't talk about the reasons why those measures might be necessary. So I quite like the background on what's happened to that individual that means this is a problem, or this is a problem, and XYZ would help' (Io7). However, they also recognised the competing demand to keep things simpler by generalising 'But yes, when it gets too individual it's a bit unmanageable' (Io7).

Furthermore, taking guidance too literally and adopting a tick-box approach was found to restrict design. When speaking about a specific resource, which offers examples of best practice, a BEP explained, 'the examples [...] are extreme, to make the point. But they say they should encourage an architect to develop a palate of their own, that suits the project' (Io6).

To encourage and allow for design processes of adoption and adaption it is important that the context of recommendations is included.

\section{Visual dialogue}

Knowledge of the target audience (discipline) is a key element in determining how guidance information should be disseminated. In describing what makes a good resource, piece of guidance or policy it was highlighted that BEPs can relate better to 'A guide written by someone who understands architecture' (Q31). Interestingly, there was a desire for guidance to include an interactive element including visiting buildings (Io5).

Visual information was the desired format of knowledge exchange by BEPs and this was a recurring theme. In facilitating design progression, illustrations demonstrating both good and bad design schemes, which emphasised 'where certain elements have or have not worked and why' (Q19), were favoured. In addition, it was highlighted that 'Illustrative guide policies work best' (Q31). Questionnaire respondents further built the case for visual resources to include content such schematic sketches (Qs10, 21, 28, 32, 33), precedent analysis (Qo4), clear simple statements with photographs of schemes and room layouts (Q33), and examples of project specific plans (Q01). The statement that 'Graphics and diagrams can be very useful in designing but without limiting the user's freedom to be creative' (Qo8), is particularly interesting as it highlights a recognised freedom for creativity within the boundaries set by guidance. In training presentations, it was highlighted that a 'mixed format' $(\mathrm{Q} 29)$ with 'pictorial presentations' (Q33) was required.

Knowledge exchange that readily supports and contributes to visual dialogue is seen as most effective by BEPs.

\section{Supporting client motivations}

BEPs and their clients both utilise guidance. Guidance that supported clients' motivations, in commissioning a building, was valued by BEPs.

The first challenge of design for the BEP was highlighted as building an understanding of the client's brief and documentation [5]. Precedent was raised as a tool to support client/BEP discussions (Q01); however, it wasn't valued by all: 'We do look at precedents and examples of similar buildings to that of what the client wants but I don't know if it is always useful.' (Io1)

In the scenario of designing a building for older people, using a care home as an example, BEPs reflected that the client/client body has the most influence in how the project develops [Table c]. However, what was interesting was that the amount of experience the client had experience was deemed to be crucial in who possessed influence. It was explained, 'If [the client is] less experienced with a less developed or non-existent brief, we have much greater influence on the design and brief

'In regards to the scenario of designing a care home for older people, who has the most influence in how the project develops?'

\begin{tabular}{rr} 
The Client/Client Body & 14 \\
Project Architect/ Designer & 5 \\
Other (The Planning System, Organisation running home, The funder) & 3 \\
Director of the Practice & 1 \\
I would prefer not to answer & 11 \\
\hline
\end{tabular}

Table c. Count of questionnaire respondent's opinions on primary influencer (mutually-exclusive multiple choice) 

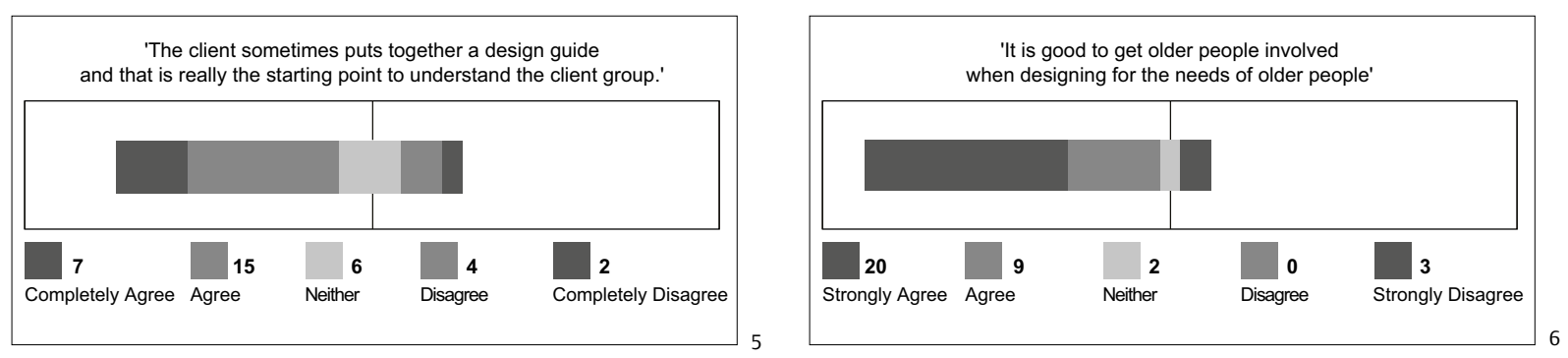

5 Count of

questionnaire

respondents'

agreement with the

primacy of client

design guide.

development process through our directors and project architects.' (Q01)

It was identified that the client is influenced by two major factors: regulations and budget. It was explained, 'Regulations play a significant part in influencing the Client/Client body.' (Q14), 'there needs to be a driver to incorporate the guidance' (Q12). Budgets can determine what is included and what is not and it was noted that 'Setting an appropriate budget is essential' (Q18). In relation to making the cost vs gain argument of accessibility and design, it was highlighted that 'any guidance that can demonstrate that designing inclusively from the outset is not necessarily more costly' (Q23) is crucial.

Guidance that informs and relates to motivations of the client was identified as a way to support discussion throughout the design process.

\section{Understanding design requirements through direct user engagement}

As well as using forms of guidance to understand user needs, evidence was reported of BEPs engaging with stakeholders (such as the client body, procurer, facilities management, representative and pressure groups) and with users (such as service users, residents, and staff) to elicit requirements. Engagement with stakeholders included briefing meetings (Qs27, 01, 11, 13, 18, 32) and maintaining links with expert advisors (Qs20, 19, 01). In addition, all respondents reported on experiences of working directly with the end-users of buildings to some degree.

To enhance understanding in designing for older people a suggestion was to, 'get older people in the design team' (Q11) or 'get as much input as you can from the end user' (Io1). Questionnaire respondents presented an ambition to involve end-users in the design process [6].

Thirty-four of thirty-five questionnaire respondents had experienced benefits of working with the users of buildings. It was recognised that 'users know what they want and how they can use a space on a practical basis' (Q21). It was recognised that user engagement had the potential to lead to better building performance in meeting daily needs (Qs07, 09) and in addressing barriers to use (Qs13, 14, Io1). Another result of this engagement was that it encouraged users to take ownership of their space

$$
\begin{aligned}
& 6 \text { Count of } \\
& \text { questionnaire } \\
& \text { respondents' } \\
& \text { agreement with } \\
& \text { involving older } \\
& \text { adults in design. }
\end{aligned}
$$

(Q23, Ro5). Further identified benefits for the design team included broader ideas of the potential contribution of the design (Q14), the demonstration of design value in meeting user needs (Qso4, 18), and avoiding misconceptions of requirements (Q32).

However, enthusiasm for direct end-user engagement was not universal among the respondents. Limited past success led to a resistance to getting stakeholders and users involved, 'In our experience, the benefits from direct resident engagement have been limited.' (Q01). Challenges and barriers were identified in relation to cost and fee levels available, the resistance of client bodies (Q01), time constraints (Q05), and the difficulties of working with users who may have limited abilities (Io1) and, when considering older adults, cognitive decline (Q01). It was highlighted that although 'useful insights and feedback' (Q05) can be gained from working with users, the opportunity to undertake this type of engagement was generally lacking (Q05) and lead to a missed learning opportunity for BEP's development $(\mathrm{Q} 28)$.

BEPs reported on various methods of engagement with end-users included speaking to older people (Qs16, 20, 27), speaking to a board of older-user representatives (Qs23, 04), through access groups (Qs15, 18), family (Q01), staff(Io1), and resident workshops (Qso1, 04. Other, more creative methods have included producing mood boards, visualisations, models, and inviting people to draw and comment on potential designs (Io5).

Interestingly a method of 'people watching' was also highlighted as having value: 'We are obsessed with people watching. Watching people is quite a good design tool in itself' (Io1). It was also highlighted that successful clients 'actively engage with residents and are continually refining their product on a scheme by scheme basis' (Q01).

It was stressed that user engagement processes were not always documented or analysed (Qs01, 32, 15, 13, Io5). Several methods of recording were identified: meeting minutes (Qs10, 11, 20, 23, 27), clients project management files (Q17), design and access statements (Q18). However there were problems identified with current engagement methods including a lack of direction on how to (Io4), having to deal with second hand information work with users within the architectural contexts 
from the client (Iog), anxiousness in knowing what types of questions to ask building users and on what priorities to concentrate on (Io2), difficulties leading and directing engagement events (Io2), and the task of balancing the fee level and time taken to undertake the research engagement (Io4). It was identified that development of a toolkit to engage users in architectural projects would helpful across a range of building projects (Io2).

The elicitation of user needs was identified by BEPs as an important element of making architecture. There was a desire expressed for working with end-users of buildings, even though both strengths and weaknesses of this are acknowledged. BEPs have recognised the need for additional tools and resources to help them engage fully with building users.

\section{Feedback on knowledge exchange from the 'front line' of built environment practice}

This article investigated the practitioners' viewpoint on knowledge exchange. BEPs play a fundamental role in enabling building users. An ageing population creates new design challenges. Through concentrating specifically on the elicitation of older people's design requirements in the UK (from thematic analysis of BEP conversations $(n=10)$ and a questionnaire $(\mathrm{N}=35)$ ) we have uncovered principles to inform future knowledge exchange design. Findings highlight the fundamentals of good communication, the desire for structured knowledge, the value of contextual guidance, the importance of a visual format for BEPs, and the need for guidance to support client motivations.

- Good Communication Fundamentals. In published documents citation of information sources and clarity were highly valued. For presented information: an unbiased agenda, experienced and engaging presenters, and good teaching practices such as use of learning outcomes were highlighted.

- Structured Knowledge. When guidance is not well structured or codified it becomes more difficult to refer to within design processes.

- Contextual Guidance.

Understanding the justification of a recommendation and the problems they address were identified as two requirements of receiving knowledge in context and building necessary understandings.

- Visual Format.

BEPs in professional practice communicate visually and so guidance that supports and contributes to this visual dialogue is desired.

- Support Client Motivations.

Both BEPs and Clients utilise guidance throughout the design process. Guidance that informs and relates to the client's motivations was identified as a way to support design discussion.

As well as using forms of guidance to understand user needs, evidence was reported of BEPs engaging directly with users to elicit requirements. A demand for guidance on methods and examples of userinteraction was identified to enable BEPs to engage effectively with their building users. It was identified that toolkits, prompts to lead conversations, and methods in documenting the process and outcome were deemed important.

Appropriate exchange of knowledge is essential for effective 'real-world' design impact. The design process can be enabled by equipping practitioners with information about user requirements and by providing support for their engagement with building users. From the 'front line' of built environment practice, we have uncovered key principles of how this knowledge can be exchanged via methods that appeal to practitioner's sensitivities.

The broader implications of these findings have the potential to support change in creating effective solutions to effective knowledge exchange. Furthermore, they may also foster inclusive dialogues between the community, educational, and professional bodies. 


\section{Notes}

1. Equality Act, 2010 C.15 (2010).

2. Adrian Cave, Inclusive Accessible Design: Legislation Maze Series (London: RIBA Publishing, 2007).

3. Donald Watson, 'Improving Practice Through Knowledge and Research', in arq: Architectural Research Quarterly, 3:1 (1999), 9-14. Available online: <http://dx.doi. org/10.1017/S1359135500001718> [accessed 2o June 2016].

4. Ellen Collins, 'Architects and Research-Based Knowledge: A Literature Review' (London: RIBA Publishing, 2014). Online: <https:/| www.architecture.com/Files/ RIBAProfessionalServices/ ResearchAndDevelopment/ Publications

Architectsandresearchbasedknowledgealiteraturereview. pdf $>$ [accessed 1 November 2015].

5. David Bartholomew, 'Sharing Knowledge' (2005), p. 1. Available online: <http://www usablebuildings.co.uk/Pages/ Unprotected/SpreadingTheWord/ SharingKnowledge.pdf $>$ [accessed 28 October 2015].

6. Simy Joy and David A. Kolb, 'Are There Cultural Differences in Learning Style?', in International Journal of Intercultural Relations, 33:1 (2009), 69-85. Available online: $<$ http://dx.doi.org/10.1016/j. ijintrel.2008.11.002> [accessed 20 June 2016].

7. Research Councils UK, 'Pathways to Impact - Research Councils UK' (2014), available online: <http:/| www.rcuk.ac.uk/innovation/ impacts/> [accessed 9 November 2015].

8. Ellen Collins, 'Architects and Research-Based Knowledge'.

9. Examples of such guidance can be sourced from: Housing LIN, which offers a wealth of resources and ideas related to housing design for older people and the HCA Housing our Ageing Population: Panel for Innovation, HAPPI Report (2009).

10. Chris Parker, Sarah Barnes, Kevin Mckee, Kevin Morgan, Judith Torrington, Peter Tregenza, 'Quality of Life and Building Design in Residential and Nursing Homes for Older People', in Ageing and Society, 24:6 (1999), 941-62. Available online: <http://dx.doi. org/10.1017/So144686X04002387> [accessed 2o June 2016]; R. Fleming, B. Goodenough, L. F. Low, L. Chenoweth, H. Brodaty, 'The Relationship Between the Quality of the Built Environment and the Quality of Life of People with
Dementia in Residential Care', in Dementia (2014), available online: $<$ http://dx.doi.

org/10.1177/1471301214532460> [accessed 2o June 2016] and A. Joseph, Y. S. Choi and X. Quan, 'Impact of the Physical Environment of Residential Health, Care, and Support Facilities (RHCSF) on Staff and Residents: a Systematic Review of the Literature', in Environment and Behavior (2015), online: http://dx. doi.org/10.1177/0013916515597027 [accessed 2o June 2016].

11. Sarah Barnes, 'The Design of Caring Environments and the Quality of Life of Older People', in Ageing and Society, 22:6 (2002), 775-89.

12. Bill Hillier, Space Is the Machine: A Configurational Theory of Architecture (London: Space Syntax, 1996).

13. Inge Mette Kirkeby, 'Knowledge in the Making', in arq: Architectural Research Quarterly, 13:3-4 (2009), 307-13. Available online: <http:// dx.doi.org/10.1017 S13591355 10000151> [accessed 2o June 2016].

14. Examples of such projects include 'Dwell' as described in the 'The Dwell Dialogue Newsletter', Issue 2 (2015), available online: <http:/| dwell.group.shef.ac.uk/ wp-content/uploads/2016/o3/ dwellnewsletter-issue-2.pdf> [accessed 12 May 2016] and the 'Open Space' project a component of which is described in this academic paper: C. Ward Thompson, 'Activity, Exercise and the Planning and Design of Outdoor Spaces', in Journal of Environmental Psychology, 34 (2013), 79-96. Available online: <http:/| dx.doi.org/10.1016/j. jenvp.2013.01.003> [accessed 2o June 2016].

15. Marc Steen, Menno Manschot, Nicole De Koning, 'Benefits of Co-Design in Service Design Projects', in International Journal of Design, 5:2 (2011), 53-6o.

16. Milene Gonçalves, Carlos Cardoso, Petra Badke-Schaub, 'What Inspires Designers? Preferences on Inspirational Approaches During Idea Generation', in Design Studies, 35:1 (2014), 29-53. Available online: <http://dx.doi. org/10.1016/j.destud.2013.09.001> [accessed 2o June 2016]

17. Christopher Alexander, Sara Ishikawa, Murray Silverstein, A Pattern Language: Towns, Buildings, Construction (New York: Oxford University Press, 1977); Christopher Alexander, The Timeless
Way of Building (New York: Oxford University Press, 1979), pp. Xv-552.

18. Herman Hertzberger, Architecture for People $(\mathrm{A}+\mathrm{U}$ : Architecture and Urbanism, 1977).

19. Joshua Prince-Ramus, AGency 10.15.2014, School of Architecture, Georgia Tech. Online video recording, YouTube (15 October 2014), available online: <https:|| www.youtube.com/ watch?v=ugtJ7F7RIUY> [accessed 15 November 2015].

2o. Bjarke Ingels, Yes Is More: An Archicomic on Architectural Evolution (TASCHEN GmbH, 2009).

21. RIBA, 'RIBA Plan of Work 2013 Overview', ed. by D. Sinclair (London, 2013), available online: $<$ https://www.architecture.com/ files/ribaprofessionalservices/ practice/ribaplanofwork 2013overview.pdf $>$ [accessed 20 June 2016].

22. David Bartholomew, 'Sharing Knowledge', p. 1.

23. David Bartholomew, 'Sharing Knowledge'.

24. Yun Gao and Kevin Orr,

'Architectural Students' Year-Out Training Experience in Architectural Offices in the UK', in arq: Architectural Research Quarterly, 19:2 (2015), 175-82. Available online: <http://dx.doi.org/10.1017/ S1359135515000391> [accessed 20 June 2016].

25. Ellen Collins, 'Architects and Research-Based Knowledge'.

26. Research Councils UK, 'Pathways to Impact'.

27. Rem Koolhaas, Bruce Mau, Jennifer Sigler and Hans Werlemann, Small, Medium, Large, Extra-large: Office for Metropolitan Architecture, (New York: Monacelli Press, 1998) 28. Bjarke Ingels, Yes Is More.

29. Inge Mette Kirkeby, 'Knowledge in the Making'.

3o. Paul Newland, James A Powell, Chris Creed, 'Understanding Architectural Designers' Selective Information Handling', in Design Studies, 8:1 (1987), 2-16. Available online: <http://dx.doi. org/10.1016/0142-694X(87)90026-3> [accessed 2o June 2016].

31. David Bartholomew, 'Sharing Knowledge'.

32. Paul Newland, James A. Powell Chris Creed, 'Understanding Architectural Designers' Selective Information Handling'.

33. Charles Hamilton Burnette, The Architect's Access to Information: Constraints on the Architect's Capacity to Seek, Obtain, Translate and Apply Information (AIA Research 
Corporation, 1979).

34. Margaret Mackinder and Heather Marvin, Design Decision Making in Architectural Practice: The Roles of Information, Experience and Other Influences During the Design Process (University of York Institute of Advanced Architectural Studies 1982).

35. Charles Hamilton Burnette, The Architect's Access to Information. 36. David Bartholomew, 'Sharing Knowledge'.

37. Ellen Collins, 'Architects and Research-Based Knowledge'.

38. Callum Lee, Amy Nettley, Matthieu Prin, Paul Owens, 'How Architects Use Research', ed. by Anne Dye (London: RIBA, 2014).

39. Ellen Collins, 'Architects and Research-Based Knowledge'.

4o. Inge Mette Kirkeby, 'Knowledge in the Making'.

41. Research Councils UK, 'Pathways to Impact'.

42. Ellen Collins, 'Architects and Research-Based Knowledge', p. 4. 43. Ibid., p. 3

44. Robert G Burgess, 'Field Research: A Sourcebook and Field Manual', in Contemporary Social Research
Series (London: G. Allen \& Unwin, 1982).

45. Colin Robson, Real World Research: A Resource for Social Scientists and Practitioner-Researchers, and Edition (Oxford: Blackwell Publishers, 2002).

46. Robert G Burgess, 'Field Research'. 47. Colin Robson, Real World Research.

48. Juliet Corbin and Anselm Strauss, 'Grounded Theory Research: Procedures, Canons, and Evaluative Criteria', in Qualitative Sociology, 13:1 (1990).

49. Colin Robson, Real World Research.

50. N. B. Robbins and R. M. Heiberger, 'Plotting Likert and Other Rating Scales', in Proceedings of the 2011 Joint Statistical Meetings (2011).

\section{Illustration credits}

arq gratefully acknowledges: Authors, all images

\section{Acknowledgements}

This work was supported by the RCUK Lifelong Health and Wellbeing Programme grant number EP/ Ko37293/1 - BESiDE: The Built Environment for Social Inclusion through the Digital Economy.

\section{Research data statement}

Supporting Data for the interviews and questionnaire data has not been made available in order to protect the confidentiality of the participants.

\section{Authors' biographies}

Lesley J. McIntyre is a Senior

Lecturer at Northumbria University. She is a co-investigator on the RCUKfunded BESiDE project. She has worked in architectural practice in the UK and the US. Her research interests focus on participatory engagement, universal design, and understanding buildings in use.

Ian Ruaraidh Harrison is a Research Assistant with the University of Dundee. He is an architectural researcher and project administrator on the RCUK-funded BESiDE project. He has previously worked in architectural practice in Scotland.

\section{Authors' addresses}

Lesley McIntyre

lesley.mcintyre@northumbria.ac.uk

Ian Ruaraidh Harrison

i.harrison@dundee.ac.uk 